\title{
Cultural History in Italy
}

\author{
AlESSANDRo ARCANGELI
}

A late recognition of cultural history as a specific dimension of research and teaching can be taken, roughly speaking, as the Italian approach to our story. On one hand, there is the legacy of an idealistic tradition that regarded all history as cultural, and therefore left limited room for a specific cultural dimension; on the other hand, resistance to theory is widespread and pragmatism does not contemplate paying much attention to international trends and debates. Having said this, a look at many historians' actual production (and familiarity with the work of other colleagues) may reveal a somewhat different picture from the official scepticism. Also, a higher degree of enthusiasm for and awareness of this orientation in historical studies is perceivable among a younger generation of scholars.

Outside the academia, the pursuit and publication of works of cultural history is even harder to pin down - but so is the general readership, in a country where books are, on the whole, a commodity that attracts a limited clientele.

Let us start with the good news. An inter-university Centre of Cultural History (CSC) was launched in March 2009 as the product of a consortium between the universities of Bologna, Padua, Pisa and Venice, with Padua acting as its current base. The Centre has a Directing Council, formed by representatives of all participating institutions, and individual membership, which also admits academics from other universities, or scholars without permanent academic affiliation. The timing of the inauguration of the Centre, which naturally results from a period of preparation, offers here the opportunity to portray a group of Italian scholars who have recently taken the initiative of choosing cultural history both as the best definition of what they are doing and as the ground for setting up an academic network. To be perfectly honest hesitations and distinctions existed even at the launch of the Centre; in particular, a group of colleagues was 
concerned about the risk of losing sight of the social side of the past and advocated the use of the expression social history of culture. As odd as it may seem in that context, this criticism is quite representative of a wider tendency within Italian academia. Unlike Germany - to take the best-known example, as well as the most appropriate on the present occasion-Italy has not experienced a significant clash between the social and the cultural. The former may be largely intended to include the latter: social history is perhaps less connected with economic history than elsewhere, and social historians may be engaged in what others would call cultural history without being fully aware of it. ${ }^{1}$

I will begin the first section of my paper by introducing the themes of research recently covered (and ongoing projects) by the Italian scholars who have more consciously and openly identified themselves as cultural historians. I will subsequently turn to institutions and the profession in general-in an attempt to assess how representative this trend is, what portion of historical studies has opted for similar methodology - and conclude with perspectives.

At the time of writing, the Padua-based Centre lists about 70 scholars, the majority of which appear on the web site $^{2}$ with a short CV. The field of expertise of members is Modern History for about 50 of them, Early Modern for just under ten, while ten more are experts in other periods or different disciplines. It is peculiar that the majority of the late modernist bulk do not hold a permanent academic position. Thus, the composition of the Centre reflects the fact that it is partly the product of the work of some research teams, which have their leaderships within the university system, but are staffed by researches who are still largely job seekers. A significant number of them are also participating in a project put forward for ministerial funding as a Research project of national interest (on these, we will soon return) two years ago. The core of the project is the visual culture of the long $19^{\text {th }}$ century history, with the transformations of the gaze brought about by the introduction of photography, up to the origins of cinema; a significant number of members of the Centre work on the relationship between history and the media. ${ }^{3}$

The proposed coordinator of the project, Alberto Maria Banti, who sits on the Centre's Directing Council, is also the author of one of the most recent and innovative history textbooks for the Italian secondary school (in particular for

1 I wish to thank Federico Barbierato and Miri Rubin for their comments on previous versions of the present contribution.

$2 \mathrm{http} / / / \mathrm{www} . c e n t r o s t o r i a c u l t u r a l e . u n i p d . i t /, 01.09 .2010$.

3 Although the 2008 application was not successful, the project was presented again in 2009. 
the last three years, age 16+). The manual is published by Laterza-a publishing house whose emphasis on philosophy and history still bears the marks of the past role of Benedetto Croce as its chief advisor-and is as systematic a cultural-historical enterprise as one can possibly expect; its late modern section (the author's main period of expertise) has subsequently been adapted for use by undergraduates. To propose to young students a historical-anthropological approach and selection of topics, complete with methodologically updated textual analyses of sources, is a praiseworthy investment in the formation of younger generations and in the future of our field and style of research. Unfortunately, the current Italian government has subsequently reformed secondary education, and from the academic year 2010/11 there will be less history and hardly any geography at all taught to precisely that age group.

Seminars are one of the Centre's main initiatives. Over the past couple of years, cultural history seminars principally held in the universities affiliated with the Centre have become a regular feature of the national academic life, occasionally inviting internationally renowned speakers. Among those organized in Spring 2010 between Padua and Pisa were the presentation of Nostalgia. Memory and passages on the Adriatic shores, a volume edited by one of the Centre's members, Rudolf Petri, and resulting from an international day conference held at the Deutsches Studienzentrum in Venice, which was preceded by a multimedia artistic event; a seminar on History and the Novel; another yet, coorganized with the Italian society of women historians, on soldiers and gender; and a discussion by Michel Vovelle on L'histoire des mentalités revisitée.

In collaboration with the Edizioni ETS, the Centre has also launched a new book series (Cultural studies. Concepts and practices). The inaugurating volume was a thought-provoking pamphlet by Lynn Hunt on cultural history in the global era, which has not yet been published in English. ${ }^{4}$

Let us now take a look at academic research from the perspective of main projects and public financial support. A core channel of governmental funding for research over the past few years has been provided by Research projects of national interest (the Italian acronym is PRIN). The fields in which the ministerial database allows searching include, beyond the title of the project, descriptions of the research objectives and of the expected innovation in relation with the state of the art. We do not have access in the same way to those projects that were not funded. We can therefore analyse themes and methods of the approved

4 Hunt, 2010. Similarly, a book series launched in Verona opened its publications with BURKE, 2009, ahead of its English edition. 
projects, not appreciate to what extent these represent a wider orientation among all applicants.

The exact phrase storia culturale was found by the search engine in a not insignificant number of projects ( 32 out of 8000 , in all disciplines and over nine years). If we consider that six proponents of the projects in question have been awarded twice (either for significantly different projects, or in a more or less explicit continuation of their previous ones), the number of financed heads of projects that have used our formula goes down to $26 .{ }^{5}$ Only in one case, however (in 1999, presented again with a wider chronology in 2002), it prominently appeared within the very (sub)title of a project (on early $20^{\text {th }}$ century women's networks across the Northern Atlantic).

Italian research is organized in 14 macro-areas, and the ones in which the projects in question fall are number 10 (Antiquity, philological-literary and arthistorical sciences), 11 (History, philosophy, education and psychology), with one only for area 14 (Political and social sciences), a 2004 project on Power and the word: religion, politics, communication; a less predictable entry from area 2 (Physics) was for a 2005 project on the history of $20^{\text {th }}$ century physics, presented as an important chapter in the cultural and economic history of the country. Among the two most relevant subject areas, the philological hosts by far more winning projects, among the ones searched, than the historical, possibly testifying to a somewhat literary declension of what cultural history is meant to be. 18 literary proponents feature in our list versus six historians (a gap that even widens if one considers the fact that five of the literary scholars were awarded funding a second time). The imbalance may be softened if we take into fuller account some of the peculiarities of the system, such as the fact that ancient historians are counted under the philological umbrella.

It may be worth taking a closer look at the six explicitly historical projects, as they should offer some indications on current research themes. For reasons of brevity, I will identify them by the name and affiliation of the project coordinator, taking for granted that it usually also comprises a series of other units in different locations. In 1999 Gabriele Turi, a Professor of modern history in Florence, led a team working on Publishing in Italy: the production and distribution of the book from the $18^{\text {th }}$ century. In the case of the project (funded in the year 2000), on the Cultural and economic relations in the Western Mediterranean during the late medieval centuries, storia culturale is mentioned within the description of the tasks of the leading unit of research, based in Pisa, in the

5 That always the same people won-it should perhaps be added-has been for a long time a point made by many, who challenge the system with allegations of unfairness. 
significant role of posing its interconnection with the economy as the qualifying feature of the team's approach (as the general title of the project states clearly enough). The project's coordinator was Marco Tangheroni, a leading medievalist who died in 2004. Still in Pisa, Adriano Prosperi, who recently retired from his chair in early modern history at the Scuola Normale Superiore, coordinated a group on The Inquisition and the control of dissent and minorities in Catholic Europe during the early modern period in 2002. The outcome of the research is a major Historical Dictionary of the Inquisition, awaiting publication shortly. ${ }^{6}$

Two projects were approved in 2006: one led in Verona by medievalist Gian Maria Varanini and devoted to Political cultures and documentary practices in communal and seigneurial Italy (XII-XIV centuries); the other, in Rome, by early modernist Marina Caffiero, on The Mediterranean of the three religions: identities, conflicts and hybridizations (XIV-XX centuries). The latter project's team, when illustrating its proposed innovative aspects, outlined some methodological preferences in the following terms:

\begin{abstract}
"In the light of a historiographical present in which the power of symbols and communicative languages have become essential to an understanding of events, the new spheres of inquiry privilege the history of mentalities and representations, cultural history, the anthropological and semiological dimension, and recover the dimension of political history by integrating it within the new vision focusing on languages, discoursive and real practices, the gap between the normative and institutional moment and actual conduct."?
\end{abstract}

Lastly, in 2007, Gian Paolo Brizzi lead a project on Academic institutions, ideological and cultural models in the formation of the elites and of political and social leadership during the Ancien Régime. ${ }^{8}$

Having individually examined the projects approved within the area comprising history, I do not intend to underestimate the level of interest we may prove for the majority belonging to the more literary-centred area 10 . To mention just a few, Mario Citroni's work on the Hellenistic culture and Roman iden-

6 In this case, whose relevance to our discourse is nevertheless undoubted, the project was picked up via the adopted search criteria only because one of the local units (Padua) used the phrase cultural history within the description of its aims.

7 http://cercauniversita.cineca.it/php5/prin/cerca.php?codice $=2006110234,01.09 .2010$ (my translation).

8 Once again, its relevance is out of question, but the actual storia culturale phrase was only contributed by the Padua unit. 
tity is centered on the Roman intellectuals' awareness of a process of cultural appropriation and of its implications, and makes an explicit plea for a culturalist approach to ancient history. Cultural modernization is studied in different contexts within two other projects - one concerned with post-World War II Spain and Latin America, the other with the oriental city from antiquity onwards. All the above projects, the duration of which is fixed at two years, were funded with resources ranging widely, according to the size of the project and/or the liberality of allocation, from a minimum of $€ 21,000$ to a maximum of $€ 185,000$. ${ }^{9}$

Beyond the occurrence of cultural history as a precise phrase, one naturally would like to know which thematic preoccupations and methodological orientations emerge from the approved projects in the most relevant fields. The 2008 awards have been recently announced and are not yet searchable: they are only available in the form of a list of coordinators, titles and allocated funds. Thus, it is not yet possible to get complete picture of their themes and methods. Some titles would suggest patterns of research interesting to our survey. ${ }^{10}$

If we go back to the last year that offers richer documentation, 2007, an examination of the 62 projects approved for the area 11 shows that 20 of them were centred on an expertise in philosophy, 17 in psychology (this category includes both medical and humanistic psychology), 14 in historical sciences, seven in education, three in geography, one in anthropology, none in physical education. Among the historical projects, the early modern period led with five, two each went to the medieval, the late modern, the history of science and palography, one to the history of Eastern Europe, none to bibliography, the history of Christianity or of religions. These indications have to be taken with caution, because the categories I just mentioned are bureaucratic pigeon-holes, but, for instance, the lack of the last two groups (Christianity and religions) does not mean that the study of religious aspects is not present within projects with a different disciplinary label; and the approach to periods which may appear underrepresented could be found inside philosophical, literary and other branches of research. Every single set of data will have its peculiarities, which discourages generalization. ${ }^{11}$ If we remember this caveat, a closer look at the 2007 projects-now

9 This is money distributed (rather than requested: the standard distance between the two figures has been varying from one year to another).

10 Just to mention one, the expression "rappresentazioni culturali" occurs in the title of a project lead by a Professor of education in Foggia devoted to the elderly.

11 For instance, in 2007 a special quota was reserved for young team leaders, and so one finds, unusually, a number of academics of lower rank as successful coordinators. As well as seeing other proposals turned down, that year also witnessed the 
that we are considering all the approved projects, not those selected under any key-word search-may help getting an idea of the spectrum of areas of research interest within the Italian historical profession.

Of the five early modern projects approved in 2007, we have already metbecause it mentioned cultural history-Brizzi's research on academic institutions and the formation of the elites. Brizzi specializes in this area and, among other commitments, directs a periodical and Inter-University Centre for the history of Italian universities. ${ }^{12}$ The other projects were submitted by Angelo Bianchi (Catholic University of Milan) for a historical atlas of education in $18^{\text {th }}$ and $19^{\text {th }}$ century Italy; by Vincenzo Ferrone (Turin) on the late Enlightenment and the crisis of the Ancien Régime in Europe; by Gigliola Fragnito (Parma) on the $17^{\text {th }}$ century Catholicisms (in the plural) of Italy, France and Spain; by Aurelio Musi (Salerno) on lay and ecclesiastical fiefdoms in Southern Italy, $15^{\text {th }}$ to $19^{\text {th }}$ century. Ferrone's work can be more appropriately labeled as intellectual history; however, the statement of the project's intended innovative aspects includes explicit reference to a dialogue with such international scholars as Robert Darnton and Daniel Roche, whose names are familiar to most of us.

The 2007 approved projects for other periods and historical specialties included the two medieval projects by Paolo Cammarosano (on civic identities and political aggregations in Italy, $11^{\text {th }}$ to $15^{\text {th }}$ century) and Franco Cardini (on the relations between Italy, Jerusalem and the Levant). The former, with comparative research between different Italian areas, repeatedly refers to cultural processes and experiences, thus interpreting institutional history in terms of an inquiry into political and administrative cultures. One of the modern projects, led by Maria Malatesta (Milan), concerns professions and power in Italy in the longue durée; the Milan unit is early modern, and among the methodological references of the project one encounters the name of Bourdieu.

Having devoted significant time and attention to one of the main channels of public funding, it should probably be added that discontent with the way the system works is strong; and that, according to some, the criteria by which projects are selected for financing tell us more about the social anthropology of Italian academia (hierarchy, networks, factions and feuds) than about research itself.

offering of significantly lower grants against the requested funds, to the extent that the scale of the projects (including the capacity of employing research support staff on a fixed-term basis) had to decrease significantly.

12 Brizzi is also the current head of the Department of history, anthropology and geography at the University of Bologna. 
Another type of governmental support is provided by FIRB (Fund for the investment in strategic research-in Italian, ricerca di base; later renamed as FIRST, Fund for the investment in scientific and technological research). As it is often the case with private resourcing for research, like that provided by the cultural foundations associated with banks, they may be advertised with one or more general topics which encourage applications, while limiting the range of subjects admitted. Thus, in 2001 one of these calls for projects was on Heritage and perspectives in the human sciences and invited to consider history, art and literature as tools for a dialogue between Mediterranean, Middle-European and Atlantic cultures. Compared with PRIN, FIRB are fewer in number but last three years and can be substantial in the amount of resources allocated. In 2008, to take the most recent and relevant, there was funding in the human sciences, with the approval of projects proposed by Mauro Antonelli on historical archives of Italian psychology, Paola Barocchi on artistic and literary culture between $19^{\text {th }}$ and $20^{\text {th }}$ century, Anna Maria Bellina on librettos for opera, Lina Bolzoni for a digital archive of words and images from $16^{\text {th }}$ century manuscripts, Claudio Leonardi for an archive of medieval manuscripts in the European cultural tradition, Enrico Pattaro on medieval juristic manuscripts, Angelo Stella on the manuscript tradition of modern writers, Loris Sturlese on medieval German philosophy. These eight projects were cumulatively granted the sum of $€ 4,200,000$. As the list suggests clearly enough, the emphasis here is in making a variety of sources more widely available (one on literary archives of the Italian $20^{\text {th }}$ century had been launched two years earlier), surely a vital precondition for their further study and interpretation.

Beyond these types of national projects, naturally, the bulk of academic research consists of locally funded (and, more often than not, individually pursued) initiatives, which are far more difficult to monitor, unless one looks at them from their result, that is, considers the profession's whole output of publications (that again is easier said than done). A combination of prolonged financial restraint with attempts to improve the system and encourage academic excellence has put pressure for an increasingly selective distribution of research funds and for the adoption of peer review schemes largely inspired by the British Research Assessment Exercise. This will have inevitable, though not entirely predictable, consequences on the nature and framework of future work.

Among institutions other than universities, the National Council of Research should at least be mentioned. Of its eleven departments, one deals with Cultural identity, another with Cultural heritage, with ten and six ongoing projects respectively. The subjects of the projects assembled under the heading of Identity include historical memory, the history of ideas (with particular focus on the 
philosophical terminology - this is the institute that produces the volumes of the Lessico intellettuale europeo series), the vocabulary of law, the Italian language, migrations and multiple identities. Under Heritage we find landscape, the conservation and fruition of heritage, the artefact as historical and material monument. Although I have no reason to suggest that a clear sign of a culturalhistorical turn is perceivable in the CNR's activities, the above initiatives may be worth mentioning as somehow related to our line of inquiry.

Italy also has a rich tradition of local and regional institutions promoting the study of history and producing publications that frequently give prominence to culture, although they may not be the most methodologically up-to-date places. Local government-from city to regional level-tends to engage in promoting or supporting ephemeral cultural events, rather than invest in lasting structures and human resources. Private (or semi-private) foundations that promote initiatives of interest for this audience include, among others: the Fondazione Benetton in Treviso (with programs on landscape and architectural history, and in the history of sports and games, as well as on its region); in Venice, the Fondazioni Cini and Levi (the latter, entirely devoted to music); in Turin, the Fondazioni Einaudi and Firpo, respectively concerned with socio-economic research and with the study of political thought; in Milan, the Fondazioni Feltrinelli (again with a core in the history of political movements and ideas) and Mondadori (for the history of publishing); in Prato, the Istituto Datini, for the economic history of the pre-industrial era; in Spoleto, the Italian centre for the study of the High Middle Ages. During the Summer of 2010 the state funding of all these institutions was the subject of hot discussions in the public opinion, following threats of complete withdrawal as the result of budget cuts.

The Italian academic system does not contemplate at any level degree programs entirely dedicated to cultural history, courses such as the ones we heard of in this conference (Aberdeen, Turku and the German degrees) or the recently announced program in Utrecht. Nevertheless, teaching modules and exams have recently appeared with the specific denomination of storia culturale. They are mostly sized at six credits, occasionally at twelve (as most other European countries, Italy sets students the target of acquiring 60 credits per year). During the academic year 2009/10, seven universities (all in Northern Italy) offer a modul on cultural history. They are normally taught by specialists in the early or late modern period (in at least one case, Genoa-where the course denomination is preceded by the clause "genres of historiography", thus offering cultural history as an example-with the contributing teaching role of a medievalist). In Bologna, the cultural history module is combined with a more philosophically oriented history of ideas, to compose a twofold program entitled, "cultural history 
and history of the systems of thought" following Foucault. In Milan a chronological delimitation is explicit in the title, cultural history of the early modern period (here, as for recruiting and careers, it may be worth mentioning that most of the teaching of history within the Italian academia falls, at least formally, into period-specific labels, and only by adopting them officially but ignoring them practically it possible to teach themes and methods across chronological barriers). Even more specifically, in the Faculty of Education of the University of Modena and Reggio Emilia, a course on offer concerns the cultural history of education (here combined with a module on education theories and methods); while in Verona, a topic taught by a colleague of mine is the cultural and social history of medicine. All taught courses belong to master degrees (the +2 of the Bologna and Sorbonne system), in the current Italian denomination, corsi di laurea magistrale. The contexts, however, differ considerably, ranging from history degrees, to literary-philological ones (Bologna), or others devoted to the study of the performing arts (Padua), languages and publishing (Milan), as well as the afore-mentioned education. The ministry's web site shows a similar pattern for last year, although, an undergraduate course of cultural and social history was then also offered at the University of Florence (within a degree program on psychology)..$^{13}$

The more traditional - and methodologically less relevant to us-wording storia della cultura (history of culture) is a clause used for many more teaching courses, this time spread throughout the country (with a significant presence in the Centre-South), although often in combination with adjectives that define them as belonging to particular fields and educational programs: the latter range from specific languages and literatures (history of the English or Anglo-American, French, German, Portuguese, Russian or Spanish cultures - in Venice, still within the faculty of modern languages, a specific course is also devoted to the theory and history of postcolonial cultures), to the culture and literature of the region hosting the university (Abruzzo at Chieti-Pescara). Anthropologists teach modules on the history of material culture, within degree courses in the humanities (at Cagliari, in Calabria, and Venice, where the level is postgraduate and the module description also includes reference to ethnographic museology). Less common is the more generic history of culture, which is attested at the Faculty of Political sciences of the small university of Teramo, where it is taught with a late modern syllabus; while, in the same faculty, an early modernist teaches a module specifically entitled history of the European culture. The Third Uni-

13 With sabbatical leaves and other circumstances that may affect the yearly offer, such slight variations are only to be expected. 
versity of Rome offers a course on the history of culture in the early modern period; Salerno has one each for the medieval, early and late modern periods (within the faculty of languages); Milan one for the late modern, another for the history of classical culture and philology (of the classical culture and tradition is the phrase used in Pisa, instead). The history of Roman culture is taught in Perugia. At Padua, the teaching of medieval culture is combined with that of the same period's mentalities. In Naples, the Faculty of Sociology has a course on the philosophy and history of culture (taught by a philosopher). At Genoa, the Faculty of Law offers a module on the history of the European legal culture, the Faculty of Humanities one on sources and methods for the history of scientific culture. At Cassino, the genius loci has suggested a specific course on the history of Benedictine culture. ${ }^{14}$

As with the case of research projects, though, it may prove too nominalistic to stop at the open denomination of cultural history courses: in order to assess the impact of the cultural turn, it would be even more relevant to judge how much of an influence it has exercised on the teaching of general history and on the determination of any other specific historical subject. To value and measure this, of course, is much less simple. The structure of professors' and lecturers' formation and career is reflected in the teaching, which usually puts an emphasis on individual periods, and leaves little room for general introductions, as well as for thematic or methodological approaches that span a wide chronology. Thus, textbooks on the history of the different periods and reading lists should be examined for an answer. Generally speaking, over the past ten years the Italian publishing system has produced a significant number of up-to-date teaching aids, which help willing academics to offer a fairly realistic and reasonably attractive image of the discipline. The orientation of authors and choices of teachers will obviously vary; however, it would be unusual today to complete a course without some exposure to the constructivist emphasis on history as an inevitably subjective discourse; to analyses such as the ones proposed by Norbert Elias or Michel Foucault as challenging keys to a deeper interpretation of the past; or to works by Peter Burke, Roger Chartier, Robert Darnton, Carlo Ginzburg or Natalie Zemon Davis - just to mention the most obvious names-

14 One could further speculate over the status of all these teaching modules by taking into account the academic rank of professors and lecturers in charge of them-but this would move us towards the tentative field of a sociology of academia on which I do not intend to improvise here (even if I wanted to, there seems to be a certain hierarchical balance in this case, not a clear-cut attribution of assignments to colleagues with more or less experience, in higher or lower positions). 
as options within lists of recommended reading. The histoire événementielle is no longer the main menu. Having said this, it would be unwise to hide the fact that this is not everyone's favourite dish, and substantially different approaches will have to cohabit for the foreseeable future.

A few of the academic and general publishers most active in the field of history are worth a glance. Il Mulino has a history catalogue subdivided in sections, partly thematic partly chronological. It currently lists 45 titles under the subcategory storia della cultura, a label that certainly includes also (although understandably not only) works with a cultural-historical orientation, as testified by several volumes by Peter Burke. (There are inevitable exceptions, but in general the Italian publishing system is receptive of the international output, and the main figures in the Anglo-Saxon or French cultural history tradition easily find their way to the Italian reader.) Laterza adopts slightly narrower headings -among them the history of the book and of libraries (50 items), of women and gender (circa 50 more), of food (about 20 titles, many of which by medievalist Massimo Montanari). A smaller but specialized history publisher as Viella has special categories, as well as on traditional chronological basis, on gender and religious history. ${ }^{15}$

Almost entirely lacking from the panorama of Italian publishing is - with few and fairly recent exceptions-the university press. This substantial difference from the standard international situation has inevitable consequences: publishing is subject to market pressures; academics may be required to cover publishing expenses; consequently, when this is guaranteed by recourse to financial support from their institutions, publishers may turn a blind eye to the quality of what is passed on to them. The peer review procedures in progress I mentioned earlier are going to have an impact on all this world; it has already been suggested that where you publish - as well as what - will be taken into fuller consideration in assessing the quality of research, and resources we distributed accordingly. Thus, individual and group strategies in writing and submitting work, in editing and publishing are likely to change significantly.

The dedicated Italian periodical possibly presenting closer family resemblances with our field is Cultural studies, now in its seventh year. Although, properly speaking, it clearly belongs to the neighbouring field indicated by its title, one historian sits in its direction,,$^{16}$ and it has hosted articles written by renowned historians, like John Brewer. Cromohs (Cyber Review of Modern His-

15 Bruno Mondadori is another publisher with a dynamic editorial policy in cultural history; the Edizioni Sylvestre Bonnard are specialized in the field of bibliology.

16 Paolo Capuzzo (Bologna), also a member of the CSC. 
toriography), the outcome of a project by scholars of the Universities of Trieste and Florence and the first entirely electronic review devoted to the history of modern historiography (first issued in 1995), also displays a general orientation very much in tune with cultural history. ${ }^{17}$

In most other cases, relevant material can be found within history periodicals either more generalist in their subject matter or methodological preferences, or dedicated to more specific issues that, however, may leave room to a culturalist approach. Le carte e la storia, Cheiron, Genesis, Giornale di storia, Passato e presente, Quaderni di storia, Rivista di storia e letteratura religiosa, Rivista storica italiana, Società e storia, Studi storici, as well as the multilingual Storia della storiografia, are among the periodicals in which both articles of original research and methodological discussions relevant to our discourse can be found in recent years.

Quaderni Storici is the internationally better-known periodical that, in the recent past, has acted as the flagship of Italian new history. It has continued to be a vital venue of research and discussion on questions that matter to us, as testified by some topics of monographic issues of recent years, from Postcolonial societies (2008), to Slavery and conversions in the Mediterranean (2007) and Cultural objects and exchanges (2006). Since the periodical was traditionally twinned to the theory and practice of micro-history, it may offer us here the opportunity to remember what, was a characteristic way of doing history a generation ago, and that, while never conquering the entire nation, has inspired a significant number of scholars with its distinctive style, which paid due attention to the cultural side of the stories it retold.

A comparatively more recent periodical whose style and approach deserve special citation is Storica. Its special issue celebrating the first 15 years of publishing (2009) included essays on symbols of politics, on historians and emotions, and on gender and world history.

Contributions by Italian scholars to foreign and international publications would pose some further issues in order to be assessed (as it is the case with books published abroad by Italian scholars, it would also cause significant problems of identification); however, on this point it may be worth registering that a member of the editorial board of Quaderni Storici, Angelo Torre, has recently contributed to a methodological discussion on Histoire et paysage on the French Annales..$^{18}$ On the other hand, the reader of Quaderni Storici would also remem-

17 One of its two directors, Guido Abbattista (also managing director of Storia della storiografia), is a member of the CSC too.

18 TORRE, 2008. 
ber that, back in 1995, the same Italian historian had accused Roger Chartier of abandoning the study of practices - and of reality altogether-for that of (mere) representations. The French historian had the opportunity to reply on Quaderni Storici and offer a lesson in theory and method; the episode, however, testified to a certain resistance from the Italian academia in accepting a culturalist approach, too quickly and unproblematically identified with postmodernism. ${ }^{19}$

Cultural historians in Italy do not have a specific professional association (other than the newly founded Centre). Few of them are members of international associating. Rather, they belong to established period-specific associations, namely, the Società Italiana per lo Studio della Storia COntemporanea (SISSCO), the Società Italiana per la Storia dell'Età Moderna (SISEM) and the Società Italiana degli Storici MEDievisti (SISMED); the latter two have special connections, but do not coincide, with the associations respectively running the web portals http://www.stmoderna.it and http://www.retimedievali.it/-both currently in the process of moving to the Verona University server. There are also, of course, more specific institutions devoted to the study of local or thematic issues, which may be relevant to cultural history: The fact remains that, partly because all Italian academic historians are recruited and progress in their careers within distinct period-specific disciplinary sectors, the above-mentioned associations and related web sites reflect better than any other their activities and (individual as well as group) self-image. It is within their ranks that we will try to identify traces of a cultural-historical turn.

The http://www.stmoderna.it portal has a register of scholars (anagrafe). Since the site is undergoing substantial restructuring, the criteria under which the research interests of individuals are indicated will also be revised. The previous (current) list does not include a specific culture-historical box one can tick. One of the closest could perhaps be storia delle idee, although everyone can easily understand that it may refer to a more traditional, philosophically-oriented intellectual history. Still, it will be interesting to know that, in a context in which profiled historians had the opportunity to indicate their expertise by ticking one or multiple boxes if appropriate (or else had them chosen for them, if their entry was created editorially) a significant number of them-over 200 out of just under 1700-expressed interest in the history of ideas (alone or in combination with others of the ten thematic fields on display).

19 Torre, 1995; Chartier, 1996. 
A key-word search through the SISSCO web site ${ }^{20}$ gives 15 scholars adopting storia culturale as a phrase within their CVs, either to describe their research interests or their teaching assignments.

Although the web site of the SISMED lists two hundred members, it does not currently allow searches throughout their CVs. Potentially interesting facilities as a list of ongoing and recent $\mathrm{PhD}$ research projects are also under construction. Reti medievali, though - a portal (also, an online periodical) providing information in English, French and Spanish, as well as Italian-collects a wide range of material of interest for the medievalist. Although a search on the exact phrase storia culturale gave a poor result, there is no doubt that many scholars on the field are operating in full awareness and tune with international trends. Nevertheless, perhaps they have a lesser tendency to identify the cultural as their main mark of identity, or refrain from joining dedicated organizations, if we have to draw conclusions from the fact that only one Italian medievalist is a member of the Padua Centre, another one of the ISCH. ${ }^{21}$

An Italian specialist of Antiquity has also joined the International Society. ${ }^{22}$ To bring together scholars of Antiquity, there is not quite an equivalent structure to the ones we have seen active for later periods, although the Association Internationale d'Épigraphie Greque et Latine (AIEGL) and Terra Italia ONLUS (Associazione per lo sviluppo e la diffusione degli studi sull'Italia romana) are prominent institutions in the field that help coordinating research.

I will now move to perspectives. In my opening remarks on the Padua Centre, I have pointed out that a significant group of relatively young late modernists - whose work is partly showcased on the Centre's own web site - are now consistently operating, with strong methodological awareness and convictions, according to a culturalist agenda.

Among early modernists, a glance to possible future developments is allowed by the fact that our association (SISEM) has launched the project of holding, a yearly, three-day seminar especially intended to offer younger scholars the opportunity to showcase their ongoing research projects and discuss them with colleagues commencing September 2010. The twenty teams that have applied the first time tell us a slightly different story from the more cautious one we are able to read among the established profession. For a start, many of the applicants (the panel coordinators, as well as the remaining speakers) have high profiles

20 http://www.sissco.it, 15.03.2010.

21 Respectively, Cristina La Rocca (Padua) and Marina Montesano (Genoa, where she also collaborates to the above mentioned teaching module).

22 Gabriella Valera Gruber (Trieste). 
of study and research. Holding a doctorate or a comparable qualification was a requirement; but what we have here is several young scholars who have pursued an international career, and are currently holding, in several cases, fixed-term research positions abroad. The age threshold of 40 may strike representatives of other countries as fairly high to qualify as young, but is justified-let alone Italian demographic and social structure, with an entrenched late departure from family nests - by the continuing poor level of recruiting in the university system.

What I meant to point out, though, are themes and methods that characterize the panels proposed for the seminars to be held in Arezzo in 2010. A cluster of them still holds on to a fairly traditional focus on the history of institutions. The large majority, on the other hand, could very easily fit under a cultural-history umbrella, either for their proposed topic, or for methodological and bibliographical points of reference, or furthermore for the featuring of culturalist key words or names in the candidates' CVs and self-presentations. Thus, there are proposed themes that present obvious family resemblances for us, such as the history of the book, cultural translation, discourses on travel and discoveries, the circulation of scientific knowledge (with science interpreted as a communication practice). Political history too appears several times with a culturalist approach, and emphasis on symbols, rituals, languages, behavioural practices, ideas and texts; economic history from the point of view of consumption; military history, as circulation of models. Other proposals concern community history, or the history of gender, religious and ethnic groups.

On the whole, therefore, if this is a reasonable sample of what the next generation of Italian scholars is up to, the perspectives of cultural history look fairly promising. The challenge is, rather, whether the national academic system will be able to recruit them and offer them a stimulating environment for teaching and research. Considering that the Italian government, as many others, has been consistently cutting university funding; that currently even the replacement of the turnover is blocked, and in the near future it will be allowed only as a limited percentage, thus actually reducing the size of the sector; that the country devotes to research and development a portion of the GDP dramatically lower than most other industrialized countries (1.09\% versus a European average of $1.85 \%$, in the most recent available figures, with France, Denmark, Germany and Austria above 2\%, Finland and Sweden above 3\% $)^{23}$-there are few grounds for optimism. The "brain drain" of Italian researchers is likely to continue; wherever

23 http://ec.europa.eu/research/era/pdf/key-figures-report2008-2009_en.pdf, 01.09.2010, p. 22. Data referring to 2006 . 
they may find employment, though, it is comforting for us to register an increasing interest for the approach to history which was the focus of this conference.

\section{Literature}

ARCANGELI, ALESSANDRO, L'histoire culturelle en Italie, in: L'histoire culturelle: un "tournant mondial" dans l'historiographie?, ed. by PHILIPPE POIRRIER, DIJON 2008, p. 41-50 (revised Italian edition in press, Verona 2010).

BURKE, PETER, Ibridismo, scambio, traduzione culturale. Riflessioni sulla globalizzazione della cultura in una prospettiva storica, trans. A. Arcangeli, Verona 2009.

CHARTIER, ROgER, Rappresentazione della pratica, pratica della rappresentazione, in: Quaderni storici 92 (1996), p. 487-493.

HunT, LYNN, La storia culturale nell'età globale, Pisa 2010.

ToRRE, ANGElo, Percorsi della pratica, 1966-1995, in: Quaderni storici 90 (1995), p. 799-829.

ID., Un "tournant spatial" en histoire? Paysages, regards, ressources, in: Annales. Histoire, Sciences Sociales 63 (2008), p. 1127-1144.

http://www.centrostoriaculturale.unipd.it/, 01.09.2010

http://cercauniversita.cineca.it/php5/prin/cerca.php?codice=2006110234,01.09.2010 http://www.sissco.it, 15.03.2010

http://ec.europa.eu/research/era/pdf/key-figures-report2008-2009_en.pdf, 01.09.2010 
